\title{
Hand hygiene practices among community Health Officers in Rivers State, Nigeria
}

\author{
*Braimoh $\mathrm{OB}^{1}$, Udeabor $\mathrm{SE}^{2}$
}

1. Department of Preventive Dentistry, Faculty of Dentistry, College of Health Sciences, University of Port Harcourt, Choba Port Harcourt, Rivers State, Nigeria

2. Department of Oral and Maximillofacial Surgery, Faculty of Dentistry, College of Health Sciences, University of Port Harcourt, Choba Port Harcourt, Rivers State, Nigeria

\begin{abstract}
Background: Health care associated infections are most commonly transmitted by the hands of Health care workers and other hospital personnel.

Objective: To investigate compliance with hand hygiene guidelines and methods of hand hygiene practice among community health officers in Rivers State Nigeria.

Methods: Self administered questionnaires were distributed to 68 community health officers. The questionnaires consisted of 19 items which contained information on bio-demographic characteristics and hand hygiene practices. Data were analysed using SPSS-16 statistical software. Proportions were compared using Chi- square test and 'p' value less than 0.05 was considered statistically significant.

Results: The response rate was $97.1 \%$. There were $11(16.7 \%)$ males and $55(83.3 \%)$ females with a male to female ratio of 1: 5 . The age of the participants ranged from $28-56$ years with a mean age of $39.7 \pm 6.7$. Washing of hands before and after contact with patient was $60.1 \%$ and $97 \%$ respectively. The difference was significant $(\mathrm{p}<0.01)$. Allergy to gloves was $15.2 \%$. About three-quarter $(77.3 \%)$ of the workers used soap and water to wash the hands when soiled or visibly contaminated. None of the workers used alcohol hand rub.

Conclusion: Though there was improved compliance to hand hygiene guidelines, this still fall short of acceptable standards. The provision and promotion of the proper use of alcohol-based hand rub may further improve compliance with hand hygiene by reducing the time required to perform it and the convenience of the method.
\end{abstract}

Keywords: Alcohol, Hand hygiene, Community health officers

African Health Sciences 2013; 13(2): 507 - 511 http:/ /dx.doi.org/10.4314/ahs.v13i2.43

\section{Introduction}

Health care-associated infections persist as a major problem in most health care settings and are important cause of negative health outcomes such as morbidity, mortality, increased health care costs and possible litigation ${ }^{1}$. Organisms that cause nosocomial infection in health care settings are most commonly transmitted by the hands of Health care workers and other hospital personnel ${ }^{2,3}$. Hand hygiene is the single most important procedure in preventing nosocomial infection ${ }^{4,5}$.

Hand washing with soap and water or alcohol-based hand rub has long been considered one of the most important infection control measures to prevent healthcare-associated infections. However, compliance by healthcare workers with

*Corresponding author:
Bashiru O. Braimoh
University of Port Harcourt
Choba Port Harcourt, Rivers State, Nigeria
Telephone: 08033562187
Email: doc_obm@yahoo.com

recommended hand hygiene procedures is unacceptably low, with compliance rates generally below $50 \%$ of hand hygiene opportunities ${ }^{6,7}$. The United State Center for Disease Control and Prevention (CDC) recommends hand-washing before and after contact with every patient ${ }^{8}$. The recommendation on hand hygiene has recently been updated, and hand washing has been replaced by hand rub as the standard of care ${ }^{9}$. In the community, hand hygiene has been acknowledged as an important measure to prevent and control infectious diseases ${ }^{10}$ and can significantly reduce the burden of disease, in particular among children in developing countries $^{11,12}$.

The introduction of primary health care (PHC) as a major cornerstone for achieving health for all and as a means of bringing health care as close as possible to where people live and work, requires the core components of PHC to be carried out by certain cadre of staff. These staff come in contact with patients, carry out treatment of minor ailment and injuries and provide immunization 
services; therefore could be involved in infection transfer process between health care workers and patients. Community health officers or workers constitute the bulk of Primary health care workers in Nigeria. Community health officers working in primary health centres in various local governments located within Rivers state were recruited for this study. These officers are licensed by the Community Health Officers' Registration Board of Nigeria to see patients, write prescriptions and carry certain medical procedures, albeit to a defined limit. Various studies have reported hand washing practices among doctors, nurses and other hospital personnel; none has focused on Primary health care workers in our environment.

The purpose of this study was to investigate compliance with hand hygiene guidelines and methods of hand hygiene practice among primary health care workers in Rivers State, Nigeria.

\section{Methods}

The study population was a group of community health officers working at various primary health centres in Rivers state. Self administered questionnaires were distributed to all (68) CHOs. The questionnaires consisted of 19 items which contained information on bio-demographic characteristics and hand hygiene practices. Data collected were entered and analysed using SPSS-16 statistical software. Proportions were compared using Chi- square test and ' $\mathrm{p}$ ' value less than 0.05 was considered statistically significant.

\section{Results}

A total of 68 questionnaires were distributed, 66 were returned giving a response rate of $97.1 \%$. There were $11(16.7 \%)$ males and $55(83.3 \%)$ females with a male to female ratio of $1: 5$. The age of the participants ranged from 28-56 years with a mean age of $39.7 \pm 6.7$. About half $(51.5 \%)$ of the respondents were between 38-47 years old and majority $(57.6 \%)$ of them have worked for between 6-15 years as shown in table 1 .

Table 1: Demographic characteristics of the community health officers

\begin{tabular}{lll}
\hline Variables & Frequency & Percent \\
\hline Age & 26 & 39.4 \\
$28-37$ & 34 & 51.5 \\
$38-47$ & 6 & 9.1 \\
$48-57$ & & \\
Gender & 11 & 16.7 \\
Male & 55 & 83.3 \\
Female & & \\
Years of work & 38 & 57.6 \\
6-15 & 17 & 25.8 \\
16-25 & 11 & 16.7 \\
26-35 & & \\
\hline
\end{tabular}

Washing of hands before wearing and after removing gloves was $56.1 \%$ and $95.5 \%$ respectively. The difference was significant $(\mathrm{p}<0.01)$. Furthermore, $60.1 \%$ of the health workers wash their hands before contact with patient, while $97 \%$ of the community health officers wash their hands after patient contact. There was statistical significant difference $(p<0.01)$ between hand washing before and after patients' contact. Allergy to gloves was reported among $15.2 \%$ of the respondents as indicated in table 2 .

Table 2: Hand hygiene practices among community health officers

\begin{tabular}{llll}
\hline Hand hygiene practices & Frequency & Percent & p-value \\
\hline Washing of hands before wearing gloves & 37 & 56.1 & 0.01 \\
Washing of hands after removing gloves & 63 & 95.5 & 0.01 \\
Allergy to gloves & 10 & 15.2 & \\
Washing of hands before patient contact & 40 & 60.1 & \\
Washing of hands after patient contact & 64 & 97.0 & \\
Washing of hands when soiled or visibly contaminated & 63 & 95.5 & \\
Use of artificial nails & 5 & 7.6 & \\
Use of natural long nails & 3 & 4.5 & \\
\hline
\end{tabular}

Table 3 shows various agents used for washing and caring for the hands after washing. About threequarter $(77.3 \%)$ of the workers used soap and water to wash the hands when soiled or visibly contaminated and $93.9 \%$ routinely wash their hands using soap and water. None of the workers used alcohol hand rub. While about two-third (60.6\%) of the health workers used bar soap to wash their hands, three-quarter $(75.8 \%)$ did not use any form of cream on their hands after washing. 
Table 3: Agents used for washing and creaming the hands by health workers

\begin{tabular}{lcc}
\hline & Frequency & Percent \\
\hline Routine washing of hands & 62 & \\
Soap and water & 4 & 93.9 \\
Antiseptic soap and water & & 6.1 \\
*Alcohol hand rub & & \\
Washing of hands when soiled or visibly contaminated & 51 & 77.3 \\
Soap and water & 15 & 22.7 \\
Antiseptic soap and water & & \\
*Alcohol hand rub & & \\
Type of soap used & 40 & 60.6 \\
Bar soap & 26 & 39.4 \\
Liquid soap & & \\
Type of cream used after washing of hands & 50 & 75.8 \\
None & 9 & 13.6 \\
Petroleum jelly & 6 & 9.1 \\
Oil lotion & 1 & 1.5 \\
Non oil based lotion & & \\
\hline
\end{tabular}

*None of the respondents used alcohol hand rub

\section{Discussion}

Transmission of most health care-associated infections has been reported to be from the hands of health care workers to patient ${ }^{2,3}$. Proper hand hygiene is the single most effective means of preventing the transfer of blood borne pathogens from staff to patient and from patient to patient ${ }^{4,5}$, 8. CDC estimates that one third of all hospitalacquired infections are caused by a lack of adherence to established infection control practices, such as hand hygiene ${ }^{13}$.

CDC recommends hand washing when hands are visibly soiled or contaminated, after barehanded touching of inanimate objects likely to be contaminated by blood, saliva, or respiratory secretions, before and after treating each patient, before and immediately after removing gloves ${ }^{14,15}$. The hand washing compliance in this study group, that provide PHC services to about $70 \%$ of the population living in rural areas; before wearing of gloves and contact with patient was $56.1 \%$ and $60.1 \%$ respectively. This is an improvement over previous studies that reported less than $50 \%$ compliance in physician and nurses particularly before patients' contact $^{16,17}$. There was also a remarkable improvement in hand washing, when the hands are visibly soiled or contaminated, after removal of gloves and contact with patients. In fact, nearly all the health care workers wash their hands when visibly soiled, after contact with patients and removal of gloves. The improvement may either be due to increase awareness of the risk of transmitting infection in health care settings, increase prevalence of health care associated infections, development of institutional infection control guidelines and policies, as well as education and training of health care personnel or may be attributable to the limitation of self-reported study where participants report was is ideal rather than real behaviour. Education in combination with performance feedback has been reported to be the most successful approach to improve the frequency and effectiveness of hand hygiene $^{18}$.

Very few of the health care workers still use long natural and artificial finger nails while seeing patients; this is strongly discouraged because the majority of flora on the hands are found under and around the fingernails. In addition, long artificial or natural nails make cleaning and donning of gloves more difficult and can cause gloves to tear more readily ${ }^{14}$.

The introduction of standard precautions has led to increase use of latex gloves and this is accompanied by increasing reports of allergic reactions to natural rubber latex among health care personnel ${ }^{15,19,20}$. The prevalence of allergic reaction in this study is $15.2 \%$ this is comparable to other studies that have reported prevalence between $2.9 \%$ and $17 \%{ }^{21-24}$. Proposed strategies to reduce the risk of reactions to natural rubber latex include the use of non-latex (e.g. vinyl) products alone or in combination with latex gloves, powder-free latex gloves, "low-protein" latex gloves and the use of lotions after hand washing ${ }^{25-27}$. In this study about a quarter of the community health officers apply cream after hand washing between 
patients and of this only 1 (1.5\%) use non-oil based lotion. It is recommended to use non-oil based lotion between patients; petroleum and oil based lotion at the end of work day. Petroleum-based lotion formulations and other oil emollients weaken latex gloves and increase permeability ${ }^{28,29}$.

The preferred method for hand hygiene depends on the type of procedure, the degree of contamination, and the desired persistence of antimicrobial action on the skin. For routine examinations, nonsurgical procedures and when the hands are soiled or contaminated; hand washing with both plain or antimicrobial soap and water is sufficient ${ }^{14}$. Plain (non-antimicrobial) soap was the major method used by this group of health workers for routine examination $(93.9 \%)$ and when the hands are visibly soiled or contaminated $(77.3 \%)$. This is in consonance with $\mathrm{CDC}$ recommendation. A number of factors constitute barrier to hand hygiene practices and these include among others lack of water, lack or shortage of sinks, lack of soap, inconveniently located sinks, lack or inadequate towels, insufficient time and often too busy ${ }^{30}$. All these can be overcome with the use of alcohol based hand rub.

It is interestingly important to note that none of the health care workers used alcohol-based hand rub for hand hygiene, despite the fact that it is currently being advocated and promoted by World Health Organisation (WHO). Presently, alcohol-based hand rubs are the only known means of rapidly and effectively inactivating a wide array of potentially harmful microorganisms on hands ${ }^{31}$. The WHO recommends alcohol-based formulation because it is fast acting with excellent microbicidal characteristics and overcome lack of accessibility to water, sinks or other facilities required to perform hand hygiene. In addition, it improves compliance with hand hygiene by reducing the time required to perform it and the convenience of the method and reduces cost ${ }^{31}$.

The study population work in poor resource remote areas with lack of access to flowing water and sink. This group will particularly benefit from the use of alcohol-based hand rub and therefore; interrupt the cross-contamination chain and disease burden. Alcohol-based hand rub is not only recommended for this group, it is also advocated for use by other health care workers as they do not need to look water, sink, soap and towels to perform hand washing before having contact with patients or wearing gloves. In addition the reluctance of washing hands in between every patient or each time before wearing gloves is simply by-passed by applying alcohol hand rub. Similarly, in consulting rooms where there are no sinks, the use of alcohol based hand rub will prevent the health workers from going out to perform hand washing elsewhere which will further lead to time wastage.

\section{Conclusion}

Though there is improved compliance to hand hygiene guidelines, this still fall short of acceptable standards. Quite a number still do not wash their hands before contact with patients. Majority use bar soap for hand washing and none of the respondents use alcohol-based hand rub. The provision and promotion of the proper use of hand decontamination agents such as alcohol-based hand rub may further help to solve common problems associated with hand-washing.

\section{References}

1. Javis WR. Selected aspect of socioeconomic impact of nosocomial infections: Morbidity, mortality, cost and prevention. Infect Control Hosp Epidemiol. 1996; 17: 552-557

2. Garner JS, Simmons BP. Guideline for isolation precautions in hospitals. Infect Control. 1983;4 (suppl): 245-325

3. Larson EA causal link between hand washing and risk of infection? Examination of the evidence. Infect Control 1988; 9: 28-36

4. Steere AC, Mallison GF. Hand washing practices for the prevention of nosocomial infections. Ann Intern Med. 1975; 83: 683-690

5. Daschner FD. Useful and useless hygienic techniques in intensive care units. Intensive Care Med. 1985; 11: 280-283

6. Pittet D, Mouronga P, Perneger TV. Compliance with hand washing in teaching hospital. Ann Intern Med. 1999; 130: 126-130

7. Lankford MG, Zembower TR, Trick WE, Hacek DM, Noskin GA, Peterson LR. Influence of role model and hospital design on hand hygiene of health care workers. Emerg Infect Dis. 2003; 9: 217-223

8. Centers for Disease Control. Guideline for hand washing and hospital environmental control. Infect Control 1986; 7: 231-243

9. Centers for Disease Control and Prevention. Guideline for hand hygiene in health care settings. MMWR Morb Mortal Wkly Rep. 2002; 51: $1-44$ 
10. Aiello AE, Larson EL. What is the evidence for a causal link between hygiene and infections? Lancet Infectious Diseases 2002; 2: 103-110.

11. Luby SP, Agboatwalla M, Painter J, Altaf A, Billhimer WL, Hoekstra RM. Effect of intensive hand washing promotion on childhood diarrhea in high-risk communities in Pakistan: a randomized controlled trial. JAMA. 2004; 291: 2547-2554.

12. Luby SP, Agboatwalla M, Feikin DR, Painter J, Altaf A, Billhimer WL et al. The effect of hand washing on child health: a randomized controlled trial. Lancet. 2005; 366: 225-233.

13. Centers for Disease Control and Prevention. Back to basics. 1997 codes emphasize hand washing. Health Care Food and Nutrition Focus 13. 1996: 8

14. CDC guidelines for Infection Control in Dental Health-Care Settings. 2003; Vol. 52 / No. RR17

15. Centers for Disease Control. Update: universal precautions for prevention of transmission of human immuno-deficiency virus, hepatitis B virus, and other blood borne pathogens in health-care settings. MMWR Morb Mortal Wkly Rep. 1988; 37: 377-388

16. Harbath S, Pittet D, Grady L, Goldmann DA. Compliance with hand hygiene practice in pediatric intensive care. Pediatr Crit Care Med. 2001; 2: 311-314

17. Alex-Hart BA, Opara PI Handwashing practices amongst health workers in a teaching hospital. Am J infect Dis. 2011. At: www.biomedsearch.com. Accessed June, 2012

18. Dubbert PM, Dolce J, Richter W, Miller M, Chapman SW. Increasing ICU staff hand washing: effects of education and group feedback. Infect Control Hosp Epidemiol. 1990; 11: 191-193

19. Zaza S, Reeder JM, Charles LE, Jarvis WR. Latex sensitivity among perioperative nurses. AORN J. 1994; 60: 806-812.

20. Bubak ME, Reed CE, Fransway AF, Yunginger JW, Jones RT, Carlson CA, et al. Allergic reactions to latex among health-care workers. Mayo Clin Proc. 1992; 67: 1075-1079.

21. Arellano R, Bradley J, Sussman G. Prevalence of latex sensitization among hospital physicians occupationally exposed to latex gloves. Anesthesiology 1992; 77: 905-908.
22. Kaczmarek RG, Silverman BG, Gross TP, Hamilton RG, Kessler E, Arrowsmith-Lowe JT, et al. Prevalence of latex-specific IgE antibodies in hospital personnel. Ann Allergy Asthma Immunol. 1996; 76: 51-56.

23. Grzybowski M, Ownby DR, Peyser PA, Johnson CC, Schork MA. The prevalence of anti-latex $\operatorname{IgE}$ antibodies among registered nurses. J Allergy Clin Immunol. 1996; 98: 535544.

24. Turjanmaa K. Incidence of immediate allergy to latex gloves in hospital personnel. Contact Dermatitis 1987; 17: 270-275.

25. CDC guideline for infection control in health care personnel. Infection Control Hospital Epidemiol. 1998; 19: 407-463

26. Berndt U, Wigger-Alberti W, Gabard B, Elsner P. Efficacy of a barrier cream and its vehicle as protective measures against occupational irritant contact dermatitis. Contact Dermatitis 2000; 42: 77-80.

27. McCormick RD, Buchman TL, Maki DG. Double-blind, randomized trial of scheduled use of a novel barrier cream and an oilcontaining lotion for protecting the hands of health care workers. Am J Infect Control 2000; 28: 302-310.

28. Larson EL. APIC guideline for hand washing and hand antisepsis in health-care settings. $A m J$ Infect Control 1995; 23: 251-269.

29. Larson E, Anderson JK, Baxendale L, Bobo L. Effects of protective foam on scrubbing and gloving. Am J Infect Control 1993; 21: 297301.

30. Pittet D. Improving compliance with hand hygiene in hospitals. Infection Control and Hospital Epidemiology 2000; 21: 381-386.

31. WHO Guidelines on Hand Hygiene in Health Care (Advanced Draft): A Summary. World Health Organization; 2005. 